\title{
Principles and Practice of Clinical Research
}

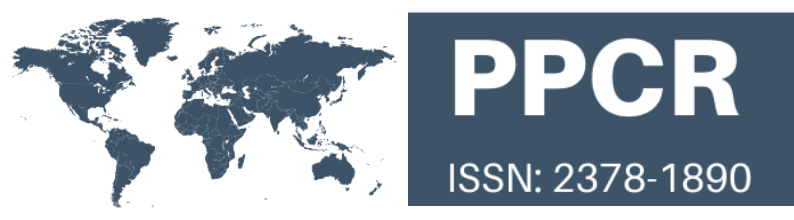

\section{Development of a distance education course on Skills and Strategies in Veterinary Communication (SSVC): a contribution to clinical research and evidence-based practice}

\author{
P. Tilley ${ }^{1 *}$ \\ ${ }^{1}$ Centro de Investigação Interdisciplinar em Sanidade Animal, Faculdade de Medicina Veterinária da Universidade de Lisboa, Portugal \\ *Corresponding authors: Paula Tilley. Centro de Investigação Interdisciplinar em Sanidade Animal, Faculdade de Medicina Veterinária da \\ Universidade de Lisboa, Avenida da Universidade Técnica, 1300-477 Lisboa, Portugal. Email: paulatilley@fmv.ulisboa.pt
}

Received March 1, 2021; accepted May 4, 2021; published September 23, 2021.

\begin{abstract}
:
Introduction: Communication training has received increased attention in the last decade and communication skills are highly important to the success of veterinary graduates. Web-based learning is becoming a major learning approach in veterinary medicine. However, there is no published study proposing an online-only, student-centered, interactive, problem-based and competency-based veterinary communication course. This course was designed with the goal of enabling students everywhere to acquire communication skills and strategies.

Methods: This course will consist of 4 modules, each comprising 3 phases with a total of 7 tasks and will be supported by media resources: Slack and Zoom platforms; Kahoot, Mentimeter, and Loom Apps. It is aimed at 4th/5th year Veterinary Medicine/Veterinary Nursing students, and at Veterinarians/Veterinary Nurses in clinical practice. Each of the modules addresses a stage of a visit and the content is based on the Calgary-Cambridge Guides. Phase 1 (individual) involves the flipped-learning concept and uses an online sharing and discussion platform. Phase 2 (team) involves a team discussion and a role-play practical class. Phase 3 is the wrap up and involves a case-based 1-hour lecture.

Conclusions: We estimate this course to be a novel element, which could be capable of developing soft skills in veterinarians even during pandemic times. It may also be an important contribution to improving clinical research and evidence-based practice.
\end{abstract}

Keywords: veterinary medicine, communication, interpersonal skills, online learning, interactive learning, problem-based learning, competency-based education, evidence-based medicine

DOI: http://dx.doi.org/10.21801/ppcrj.2021.73.3

\section{Abbreviations:}

SSVC: Skills and Strategies in Veterinary Communication

\section{INTRODUCTION}

Communication training has received increased attention in the last decade, however, veterinarians still struggle with the dual role of scientific advisor and proactive communicator. The predominant approach seems to be that of paternalism, where veterinarians set the consultation agenda, take the role of the guardian, and assume that the client's values match their own (Barde et al, 2017).

Teaching and learning communication has been addressed by various authors in the field of veterinary medicine to promote the development of communication programs for the veterinary profession 
to a level of proficiency. This has been supported by evidence base regarding the impact of communication on clinician-client interactions and outcomes of care since communication should be taught and learned with as much rigor as every other aspect of clinical competence and should be part of the veterinary programs (Kurtz, 2006). A meta-analysis of multiple surveys intended to evaluate which competencies were more important to the success of graduate veterinarians and showed that communication skills are currently the only professional competency that can be confidently demonstrated as highly important to veterinary graduate success (Cake et al, 2016).

In English-speaking countries, the CalgaryCambridge consultation model is adopted in veterinary colleges, but this does not happen in many other countries. The need for post-educational training in clinical communication skills has also been emphasized (McDermott, 2018; Pun, 2020). The Calgary-Cambridge model, adapted for veterinary use, is the primary model through which the skills required for conducting and communicating within a veterinary consultation are taught in both the undergraduate curriculum and in continuing professional development (McDermott, 2018).

In the UK, the Royal College of Veterinary Surgeons has introduced the "Day one Competences" (RCVS, 2001; RCVS, 2020), which was later adopted by the European Association of Establishments for Veterinary Education (EAEVE) and the Australasian Veterinary Boards Council (AVBC). The North American Veterinary Medical Education Consortium "Roadmap" report (NAVMEC, 2011) also favored the expansion of "soft" skills within core graduate-level competencies. In the same year, a partnership was established between the American Veterinary Medical Association (AVMA) and the American Animal Hospital Association (AAHA) with the focus of assisting small-animal practitioners to enhance communication skills which are essential to improve the veterinary-client-patient relationship (VCPR). Soon after, the American Association of Equine Practitioners (AAEP), proposed a 3-year strategic plan towards improving the VCPR and pointed out that equine practitioners often have to communicate their recommendations through trainers or other caregivers, which increases the complexity and challenges (Kanara and Werner, 2012).

Still, more than half of the most recent graduates (post-2000) felt that veterinary communication skills training did not prepare them well to communicate with clients, therefore there seems to be room for improvement (McDermott, 2018).

Furthermore, there is a lack of studies focusing on continuous professional training for large-animal veterinarians, suggesting a lack of emphasis on the communication skills of large-animal veterinarians (Moore et al, 2016).

In a recent integrated review of the role of communication in veterinary clinical practice (Pun, 2020), it was pointed out that there is a gap of knowledge in this field since limited studies have taken a holistic approach to the role of communication in veterinary practices, by exploring the interactions between veterinarians, clients, and other related professionals.

Web-based learning is becoming a major learning approach in veterinary medicine, although no study has yet reported the same benefits (Artemiou et al, 2014). Nevertheless, only studies published in English have been widely read and the comparison of diverse studies to understand the cultural differences between Eastern and Western countries would be desirable (Pun, 2020). Similarly, a web-based program in veterinary communication skills and strategies could be inclusive and could allow students to be involved in a multicultural learning experience which should be enriching for all.

Since 2003, the Institute for Health Communication (IHC) has developed, a series of 16 educational modules and training films on skill-based communication topics in veterinary medicine. These modules have been shared with 51 schools of veterinary medicine in the United States, Canada, Australia, Portugal, Japan, and South America during IHC's annual faculty (train-the-trainer) presential course (IHC, 2021). However, this is an asynchronous online course, where interaction is less favored.

To the best of our knowledge, there is no published study that has proposed an online-only, studentcentered, interactive, problem-based, and competencybased veterinary communication course.

This paper aims to contribute to the transfer of knowledge during this time of pandemic and eventually to cause a reform in education through the implementation of an online-only educational program in veterinary communication, focusing on enhancing communication skills and strategies, in both small and large animal clinical contexts.

The hypothesis that we intend to explore is whether a group of sixty students (4th and 5th-year veterinary medicine and veterinary nursing students, as 
well as veterinarians and veterinary nurses in clinical practice) entering an online-only veterinary communication course will show significantly superior communication skills and strategies in the roleplay assessment of the 12th week (after intervention) as compared to the 1st week (before intervention baseline).

The general goals of this course are to learn and to improve veterinary communication skills and strategies (competency-based education) interactively and make a difference at each step of the consultation. Also, to consolidate these skills and strategies by applying them in practice (purpose, autonomy, mastery).

The secondary gains will be the chance to work in a multicultural, multilingual environment, being involved in a team of individuals at different professional levels and being exposed to problem-based learning.

\section{MATERIAL AND METHODS}

This course was designed to be an online-only interactive course that enables students everywhere to have the possibility of acquiring communication skills and strategies.

\section{Teaching methodology and use of technology}

The SSVC course is student-centered and involves 4 modules. Each of these modules has 3 phases, which in total involve 7 tasks (Figure 1). Students must complete task 1 before doing any other tasks.

In phase 1, in tasks 1,2 , and 3 , we will use the flipped-learning concept and the Slack platform(https://slack.com/intl/pt-pt/) to share materials and to assess the peer's materials for both correction and completeness. In phase 2 , in tasks 4, 5,

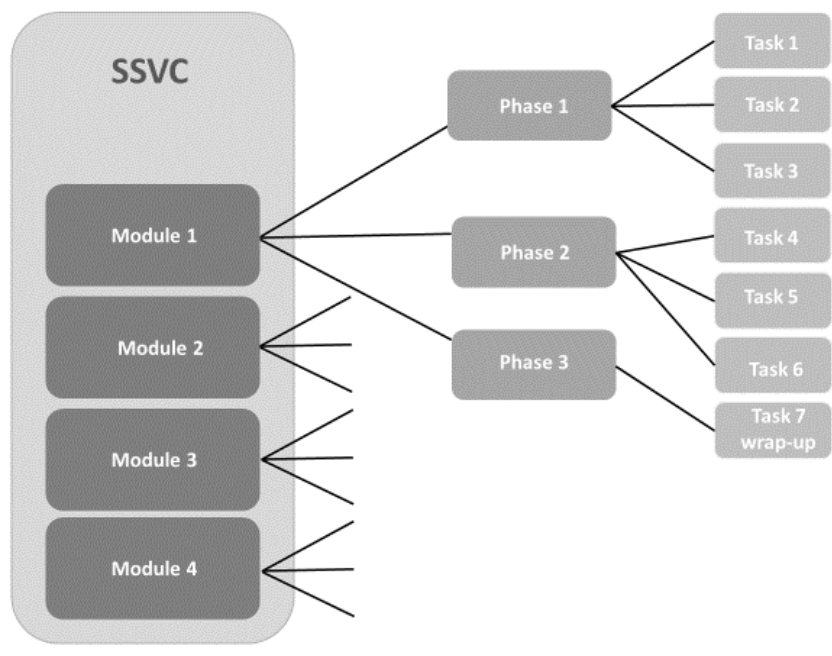

Figure 1. SSVC course structure and 6, we use team-based learning through roleplaying. Here we will employ Zoom (https://zoom.us/pt-pt/meetings.html), with the possibility of using Breakout Rooms and of Recording videos. In Phase 3, we will use Slack for the students to be able to post their questions for task 7 and Zoom for the lecture.

The use of an online sharing platform (Slack) and an online video interactive platform (Zoom) is the main technological feature of this course. These were chosen to allow students to interact both in writing (Slack) and in speaking/acting (Zoom), and also to enhance critical thinking and long-lasting learning of skills and strategies.

In Phase 3, Zoom is used for the lecture together with Mobile Learning (mLearning) using Kahoot (https://kahoot.com) and Mentimeter (https://www. mentimeter.com).

The use of Kahoot and Mentimeter for one of the tasks was chosen for being interactive and easy to use. Kahoot $₫$ is a game-based learning platform with usergenerated multiple-choice quizzes that can be accessed via a web browser or the Kahoot app on a mobile phone. Mentimeter Word Cloud $\AA$ is an app that enables users to share knowledge and real-time feedback through mobile phones and can post questions easily and within minutes. Also, it has the capacity to aggregate responses from every participant anonymously.

Loom (https://www.loom.com/my-videos) will be used in Phase 2, for task 4, to record short feedback videos for the students. Loom $®$ is a free app where we can record and share video messages of our screen, camera, or both. This is faster than typing an email or meeting live and is very useful to give feedback to students.

\section{RESULTS}

\section{1 - Course description}

The SSVC course is aimed at 4th and 5th-year Veterinary Medicine and Veterinary Nursing students, and Veterinarians and Veterinary Nurses in clinical practice. It sets the basic knowledge (principles of effective communication and types of communication skills) which will be addressed as the threshold concepts (evidence-based skills and strategies that make a difference) needed for future deep long-lasting learning (to be applied in practical clinical settings).

As stated in Material and Methods, the course content is divided into 4 Modules, each one of them addressing a stage of a veterinary visit (Table $\mathbf{1}$ ): 
Module 1 - initiating the session; Module 2 - gathering information and structuring the interview; Module 3 building the relationship, interactive explanations and planning; Module 4 - closing the session.

\begin{tabular}{|c|c|c|}
\hline Module & Contents & Topics \\
\hline 1 & $\begin{array}{l}\text { Initiating the } \\
\text { session. }\end{array}$ & $\begin{array}{c}\text { Problems; Skills; Preparation; } \\
\text { Establishing initial rapport; } \\
\text { Identifying reason for consultation }\end{array}$ \\
\hline 2 & $\begin{array}{l}\text { Gathering } \\
\text { information and } \\
\text { providing } \\
\text { structure to the } \\
\text { interview. }\end{array}$ & $\begin{array}{l}\text { Problems; Skills; An integrated } \\
\text { clinical method of information } \\
\text { gathering; Questioning techniques; } \\
\text { Clinical reasoning effect on the } \\
\text { process of information gathering; } \\
\text { Making organization open; } \\
\text { Attending to flow }\end{array}$ \\
\hline 3 & $\begin{array}{l}\text { Building the } \\
\text { relationship. } \\
\text { Explanation and } \\
\text { planning as an } \\
\text { interactive } \\
\text { process. }\end{array}$ & $\begin{array}{l}\text { Problems; Skills; Non-verbal } \\
\text { communication; Developing } \\
\text { rapport; Involving the client; } \\
\text { Providing correct amount and type } \\
\text { of information; Recall and } \\
\text { Understanding; Incorporating the } \\
\text { client's perspective; Shared decision } \\
\text { making }\end{array}$ \\
\hline 4 & $\begin{array}{c}\text { Closing the } \\
\text { session. }\end{array}$ & $\begin{array}{l}\text { Prevention of problems in closing by } \\
\text { behaviors earlier in the visit; Skills; } \\
\text { Inefficient endings associated with } \\
\text { behaviors during closure. }\end{array}$ \\
\hline
\end{tabular}

Table 1. Summary of contents of the SSVC course modules

The course dynamics and interaction for learning include 3 phases in each one of these modules (Appendix 1).

Phase 1 (individual) involves the flipped-learning concept and uses an online sharing and discussion platform. The first three tasks are carried out in this phase. -Task 1 (individual) reading the 2 given materials and posting the summary of one of them. -Task 2 (individual) searching and posting material (video, paper, image) and commenting on it. •Task 3 (individual) assessing the comment posted by a colleague on material.

Phase 2 (team) involves a team discussion and uses a role-play practical class, both in an online interactive platform. The next three tasks are carried out in this phase. Task 4 (team) studying the given roles in a role play and preparing a short video to show the class. Task 5 (team) building a table of more and less positive points to present in class, regarding the other teams' role play videos. Task 6 (team) each group formulates one question about the role-plays and the most voted question in Kahoot (https://kahoot.com/) is then answered by all groups in Mentimeter Word Cloud (www.mentimeter.com).
Phase 3 is the wrap-up and involves a case-based 1-hour lecture in the online interactive platform. The last task is carried out in this phase. Task 7 (individual) is entitled "Who has a spectacular question to ask now?" where the students post their questions before the lesson on the online sharing and discussion platform and have to attend the lecture.

The structure of the lecture is as follows: A - 9 minutes to summarize the main topics taken from the individual posts made by the students in Phase 1 and 1 minute to answer one of the students posted questions; B - 10 minutes to summarize the main more and less positive points reported by the teams regarding the role-plays; $\mathrm{C}$ - 20 minutes to present the module topic, integrating the topics presented in A and B; D - 20 minutes case-based discussion, based on a 5-minute video of a real consultation.

\section{2 - Course content (Table 1)}

The course content is based on the Calgary-Cambridge Guides (Adams and Kurtz, 2017).

\section{1. - Module 1 - Initiating the session (2 weeks) Week 1}

Principles of good communication. Problems in communication. Preparation for the next patient. Establishing the initial rapport, greetings, and introductions. Demonstrating interest and respect, attending to the client's and patient's physical comfort.

Week 2

Identifying the reason for the consultation. Opening question. Listening to the client's opening statement. Attentive listening (wait time; facilitative response; nonverbal skills; picking up verbal and nonverbal cues). Confirming and screening. Agenda setting.

\section{2. - Module 2 - Gathering information and structuring the interview (4 weeks) \\ Week 3}

Problems in communication. The content of information gathering. An integrated clinical method. Definition of biomedical and client perspectives - the importance of exploring both perspectives (supporting, understanding, and building a relationship; the biomedical model does not provide all information; discovering client's perspectives can aid diagnosis and make more effective and efficient interviews; developing groundwork for explanation and planning). An 
alternative template for the content of information to gather (sequence of events; signs; systems review; client's perspective; background information/context).

Week 4

The process skills of information gathering (exploration of patient's problems and client's concerns; questioning techniques; open and closed questions; getting more focused - moving from open to closed questioning)

Week 5

The process skills of information gathering (eliciting the client's story; attentive listening; facilitative response - encouragement, silence, repetition, paraphrasing, sharing thoughts; picking up verbal and non-verbal cues; clarification; internal summary; language; discovering the client's perspective; the relationship between animal and client).

Week 6

Providing structure to the interview. Making organization overt (internal summarizing; signposting and making transitions). Attending to flow (sequencing; timing).

\section{3. - Module 3 - Building the relationship, interactive explanations, and planning (4 weeks)}

\section{Week 7}

Relational coordination (shared goals, shared knowledge, mutual respect, frequent/timely/accurate communication, communication geared toward problem-solving). Problems in building the relationship.

Week 8

Using appropriate non-verbal communication. Reading the non-verbal cues of clients. Use of notes and computers. Developing rapport. Emotional and cognitive empathy. Involving the client. Sharing the thoughts. Providing rationale.

Week 9

Problems with the amount and type of information that we give. Problems with the language we use. Making sure people recall and understand the information. Whom to involve in explanation and planning. Involving people in decision-making to the level that they want. Providing the correct amount and type of information. Assessing the client's starting point. Asking what other information would be helpful. Internet use and health literacy.

Week 10
Appropriate times to give explanations. Skills that improve recall and understanding. Incorporating the client's perspective for a shared understanding. Planning by shared decision making. Discussing and offering options. Making sure people follow through with the plans made. Influencing client's motivation to change health practices. Importance of adherence versus compliance.

\section{4. - Module 4 - Closing the session (2 weeks) \\ Week 11}

Behaviors during closure that are associated with inefficient endings. Skills for closing the session (planning - contracting and safety netting; ensuring appropriate point of closure - end summary and final checking).

Week 12

What behaviors and communication skills earlier in the visit prevent new problems arising during closure. The overall use of the Calgary-Cambridge Guides.

\section{3 - Learning Methodology (Appendix 1 and Table 2)}

In this course, various methods are proposed to enhance learning. Care was taken to include encoding strategies, engaging strategies (both top-down and bottom-up), strategies to develop critical thinking, intrinsic motivation enhancement, extrinsic motivation, consolidation, and retrieval strategies, all having the purpose of ensuring that students can reach autonomy, purpose, and mastery.

\begin{tabular}{|c|c|c|}
\hline Encoding & \multicolumn{2}{|c|}{$\begin{array}{l}\text { Acquiring information (individual); Student } \\
\text { interaction (Team); } \\
\text { Lecture involving different dynamics and ending with } \\
\text { student interaction. }\end{array}$} \\
\hline \multirow[b]{2}{*}{ Attention } & Bottom-Up & $\begin{array}{l}\text { Conversation interaction; Lecture } \\
\text { with different dynamics. }\end{array}$ \\
\hline & Top-Down & $\begin{array}{l}\text { Priming the brain (telling students } \\
\text { the relevance of learning topics); } \\
\text { Peer assessment of role-plays; } \\
\text { Answering questions. }\end{array}$ \\
\hline $\begin{array}{l}\text { Consolidation } \\
\text { / Retrieval }\end{array}$ & \multicolumn{2}{|c|}{$\begin{array}{l}\text { Assessing comment from a colleague; Summary of } \\
\text { student's comments in lecture; Role play and table of } \\
\text { positive points; Case-based discussion; Formulating a } \\
\text { question; Kahoot; Mentimeter Cloud. }\end{array}$} \\
\hline $\begin{array}{l}\text { External } \\
\text { Motivation }\end{array}$ & \multicolumn{2}{|c|}{$\begin{array}{l}\text { Grading of tasks; Assessment of posts and role-play } \\
\text { roles by peers; Practical exam (Role-Play). }\end{array}$} \\
\hline $\begin{array}{c}\text { Internal } \\
\text { Motivation }\end{array}$ & \multicolumn{2}{|c|}{$\begin{array}{l}\text { Use of practical contexts and applicable examples } \\
\text { and scenarios; Student interaction; Variety of tasks. }\end{array}$} \\
\hline
\end{tabular}

Table 2. Summary of the SSVC course learning methodology 
At the end of the course, students are encouraged to apply for the "Bayer Excellence in Communication Award", a healthcare scholarship which encourages veterinary students to learn how to effectively communicate with pet owners.

\section{4 - Assessment and Grading (Table 3)}

The main tasks are assessed by teachers and by interns and we propose a performance-based assessment, using realistic recreation of assessment scenarios. Therefore, in task 4 (weekly role-play), the feedback from teachers /interns is given in a short video, following a scorecard. This scorecard includes standardized scoring rubrics to improve the consistency of scoring between students. At the end of the course, there is also a graded real-life scenario assessment, which is the practical exam involving a roleplay, assessed only by the teachers, using the same scorecards.

Additionally, there is peer assessment in tasks 3, 5, and 6, and group assessment is carried out in tasks 4 and 5.

Grading is issued according to Table 3, where the majority of the points are attributed to tasks 4 (team roleplay vídeo) and 5 (building a table with more / less positive points regarding other teams' role play videos), each worth 20/100 points. Also, the practical final examination (role-play between 2 students) is worth $30 / 100$ points. The remaining $30 / 100$ points are distributed by tasks 2, 3, 6, and 7 .

\begin{tabular}{|c|c|c|}
\hline Task 1 & $\begin{array}{l}\text { Read the } 2 \text { given materials and post the } \\
\text { summary of one of them }\end{array}$ & - \\
\hline Task 2 & $\begin{array}{l}\text { Search and post a material (video, paper, } \\
\text { image) and comment it }\end{array}$ & 10 \\
\hline Task 3 & $\begin{array}{l}\text { Assess the comment posted by a colleague on } \\
\text { a material }\end{array}$ & 10 \\
\hline Task 4 & $\begin{array}{l}\text { Study the given roles in a role play and prepare } \\
\text { a short video to show the class }\end{array}$ & 20 \\
\hline Task 5 & $\begin{array}{l}\text { Build a table of more and less positive points to } \\
\text { present in class, regarding the other team's } \\
\text { role play videos }\end{array}$ & 20 \\
\hline Task 6 & $\begin{array}{l}\text { Each group formulates one question about the } \\
\text { role-plays and the most voted question in } \\
\text { Kahoot is then answered by all groups in } \\
\text { Mentimeter Word Cloud }\end{array}$ & 5 \\
\hline Task 7 & $\begin{array}{l}\text { "Who has a spectacular question to ask now?" } \\
\text { - the students post their questions before the } \\
\text { lesson and have to attend the lecture }\end{array}$ & 5 \\
\hline \multirow{2}{*}{$\begin{array}{c}\text { Practical } \\
\text { examination }\end{array}$} & Role-play between 2 students & 30 \\
\hline & TOTAL & 100 \\
\hline
\end{tabular}

Table 3. SSVC course assessment and grading

\section{5 - Overview of methods (Figure 2)}

In each module, the learning occurs throughout the phases and tasks performed by the student.

Lectures occur once a week and wrap up the contents by incorporating a summary of the posts made by the students in Phase 1 and of the positive points pointed out by the students in Phase 2 . The lectures also include the discussion of one of the questions made by the students and end with a case discussion.

Between lectures (off-learning collaboration/assignments) the students have to do individual and teamwork: read 2 given materials; post and comment on material and assess the comment posted by a colleague; prepare and carry out a role-play, assess the more and less positive points of their peers role-plays; formulate a question about the role-plays and formulate a question about the topic of the week.

The course lasts for 12 weeks and can take 60 students. Module 1 takes 2 weeks, module 2 takes 4 weeks, module 3 another 4 weeks, and module 4 is again 2 weeks.

Lectures are 1 hour long and are done once a week on Thursdays.

Role-play practical classes take place on Tuesdays and occupy 4 hours. Each group of 5 students (roles: veterinarian, veterinary nurse, intern, two animal tutors) does one role-play per module. For this purpose, modules 1 and 4 have 6 groups of 5 students per week, there being 10 minutes per role-play; modules 2 and 3 have 3 groups of 5 students per week, there being 15 minutes per role-play.

Task 5 and task 6 take over the rest of the practical class time. For these tasks, students are first placed in Zoom Breakout Rooms for individual group work and then are joined again for interaction between groups.

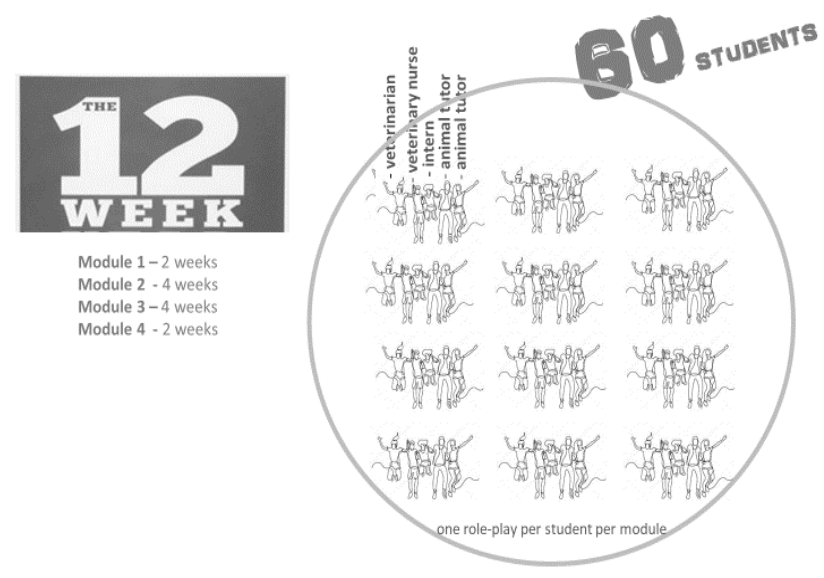

Figure 2. Overview of methods 


\section{DISCUSSION}

\section{1 - Learning methodology}

Hereafter, we discuss how the methods proposed with the intention of enhancing learning can be put into practice in the different phases.

\section{1. - Encoding strategies}

Four encoding strategies are commonly described: organization (clustering of related items of content into categories that illustrate relationships), schema activation (activating relevant prior knowledge so that new information can be connected to it), elaboration (increasing the number of connections among items of existing knowledge); imagery (forming mental pictures) (Schellenberg et al, 2011).

For organization, at the beginning of each module, the students are given the objectives, the list of topics, and the materials (videos, textbook chapters, papers) where they can read the contents. Also, there are strategies for acquiring information included in the tasks involved in all phases (1, 2, and 3), facilitating schema activation.

For elaboration and imagery, student interaction occurs in phases 1 and 2 . In phase 1, task 3 (assessment of the comment posted by a colleague on material) is a form of interaction; in phase 2 , tasks 4,5 , and 6 , all represent interaction, either through role-play with their peers, or finding the more and less positive points in their peers' roles, or even by formulating and answering a question. In phase 3 , encoding is further enhanced by involving different dynamics and ending with student interaction.

\section{2. - Engaging strategies}

Providing students with facilitated interaction opportunities, to discuss and reflect on what they have understood enables them to learn about clinical skills online more effectively. In one study, regular announcements, collaborative work, real-world projects, and structured or guided discussions were most beneficial to respondents (Bintley et al, 2021). To engage students and drive their attention, both topdown and bottom-up strategies are proposed in this course.

\section{Bottom-up strategies}

The conversation in all the activities involving interaction through group discussion (this occurs in phase 2 , in tasks 4 and 5 , and phase 3 , in part D of the lecture). Interaction in phase 2 , in task 6 , through
mLearning, which according to Fregni and Sanchez J (2020), enhances communication between participants and instructors. Also, in phase 3 , the teacher moving and varying the tone of voice in parts $A, B$, and $C$ of the lecture, as well as having the different activities A, B, C, and $\mathrm{D}$, using the students' posts and points in parts $\mathrm{A}$ and $B$ of the lecture, and showing a short video, is aimed at improving emotional engagement.

Engagement is an important factor in online learning, where attrition rates are usually higher. Interaction is essential in student engagement and should be part of the online learning environment (Bolliger and Martin, 2018).

\section{Top-down strategies}

Priming the brain by telling students at the beginning of each module why the information being taught is important for their lives. Also, in phase 2, having students' roles being commented on by their peers (tasks 4 and 5) and then having students answering a question in task 6.

Furthermore, setting up a contract with the students at the beginning of the course explaining why the need to turn off distractions (smartphones, computers) is intended to increase top-down attention. Also, activities like the role play in phase 2 or the casebased discussion in phase 3 , are aimed to contribute to a continuous enhancement of intrinsic motivation and at increasing top-down attention.

Top-down mechanisms are those initiated via mental processing at the level of the cerebral cortex (Taylor et al, 2010).

\section{Intrinsic motivation strategies}

This course has an interactive character, uses a variety of tasks, practical contexts, and applicable examples and scenarios. Cases cover an array of veterinary contexts, including gathering history on a healthy patient, examining a live animal, acute illnesses, chronic illnesses, palliative care, euthanasia, ethics, animal welfare, client socioeconomic challenges, and more.

By facilitating experimental learning opportunities (namely the role-plays) within a safe environment for the advancement of clinical communication skills, we also intend to enhance intrinsic motivation, which in turn may increase autonomy, purpose, and mastery.

When students work collaboratively in the classroom, their intrinsic motivation increases because their self-confidence enhances. They also develop positive attitudes to the learning content and they respect each other more and easily accept ideas that 
come from others. Furthermore, through implementing different strategies and interesting activities teachers can help students realize that what they study is important to learn (Serin, 2018).

\section{Extrinsic motivation strategies}

The grading of the tasks performed by the students, the assessment of posts by peers, and the assessment of role-play roles also by peers. Finally, the practical exam (role play).

As pointed out by Serin (2018), although the use of extrinsic motivators positively influences people and leads them to the attainment of a goal, their effects do not last long. However, they can provide people pleasure and satisfaction from completing a task. Also, as Fregni (2019) points out, they help maintain a rhythm and create a routine.

\section{3. - Consolidation and Retrieval Strategies}

According to Fregni (2019), teachers should dedicate part of their teaching to exercises that will retrieve, instead of just giving new material to be encoded, and this retrieval should involve deep analysis. Furthermore, Hattie and Donoghue (2016) refer that consolidation of surface learning can be achieved through practice testing, rehearsal, help-seeking, time on task, reviewing records, practice with help of an expert, receiving feedback from practice, amongst others. The learning strategies that develop the learner's proficiency to consolidate deeper thinking include self-verbalization, self-questioning, selfmonitoring, self-explanation, self-verbalizing the steps in a problem, seeking help from peers and peer tutoring, collaborative learning, evaluation and reflection, problem-solving, and critical thinking techniques.

Consolidation strategies should occur in phase 1 , in task 3 (assessing a comment from a colleague), and in the lecture, in parts A and B (summary of student's posts and summary of positive points from the role play assessment by peers).

Both consolidation and retrieval should take place in phase 2, in task 4 (role play) and task 5 (building a table of positive points about the role play assessment by peers). Also in phase 3 , in part $D$ of the lecture (casebased discussion), and in task 7 (formulating a question). Further retrieval should be achieved in phase 2, in task 5 (formulating a question), in task 6 (Kahoot and Mentimeter cloud), and in the practical exam (roleplay).

\section{4. - Autonomy, Purpose, and Mastery}

This program should provide the opportunity for learners to continue to develop group process skills and self and peer assessment skills to continuously build autonomy, purpose, and mastery. We expect that students develop all of these from the role-play in Module 1 until the role-play in Module 4.

As the role-play interactions are recorded (videos) and students have digital copies of their interviews, this should allow them to enhance their learning through self-assessment, discussion, and peer feedback, to expand their repertoire skills, therefore, their mastery.

Furthermore, the use of practical contexts and applicable examples and scenarios, and the stimulation of student interaction, not only increases intrinsic motivation but enhances attention, to lead the students to construct their approaches for future communication in clinical settings. This way they should acquire the tools needed to have autonomy in future clinical scenarios.

\section{5 - Strategies to develop Critical Thinking}

The assessment of peer's posts in phase 1 , in task 3 , the elaboration of a table with the more and less positive points of the colleagues' role-plays in phase 2 , in task 5 , and phase 3 , in part $\mathrm{D}$ of the lecture, in the case-based discussion.

\section{2 - The Role-Play Method}

The most relevant feature in this course is the role-play method and we could say that all other methods used here lead up to the role-play.

The role-play is regularly used to develop communication skills in medical students. It is used as a training method to acquire knowledge, attitudes, and skills. For skills acquisition, the chance for repeated opportunities with feedback is critical (Nestel and Tierney, 2007).

Simulation has unique features, such as the ability to be tailored to train technical skills or other abilities and attitudes such as teamwork, communication skills, and leadership, as well as being a reliable assessment method (Jones et al, 2015).

Simulations should provide a safe, supportive, motivational and learner-centered environment and should ensure the skills are consolidated and aligned with other curricula activity. Also, they should provide access to expert tutors who are available, only when needed, and they should map on to real-life clinical experience (Nestel and Tierney, 2007).

Moreno-Guerrero et al (2020) carried out a study to evaluate if the application of the role-playing method 
promoted an improvement of attitude variables and practical skills. The results showed that the students positively valued the application of the method, obtaining better scores in the set of variables studied, especially in motivation, creativity, and collaboration.

\section{3 - Method implementation during the pandemic}

The implementation of lockdown measures during the present COVID-19 pandemic was rather sudden and very little preparation was possible when moving from the traditional in-class learning to the e-learning format. In most cases, the same materials and methods were used for e-learning. We believe that, if we want to implement e-learning or even a hybrid model, the structure, the methods, and the materials used, have to be conceived for this purpose.

According to Li and Lalani (2020), the unplanned and rapid move to online learning, with no training, insufficient bandwidth, and little preparation, will result in a poor user experience that is unconducive to sustained growth. Unstable internet network, for example, constrains many students. Nevertheless, online learning has been shown to increase retention of information and take less time, meaning the changes may be here to stay. Students can learn at their own pace. Major events often trigger rapid innovation. This pandemic has disrupted an education system that seemed to already be losing its relevance.

Apart from traditional in-class teaching, various types of teaching, which involve virtual teaching in some form, have been described. We can have e-learning (electronic learning), b-learning (blended learning, hybrid model), m-learning (mobile learning), u-learning (ubiquitous learning). There is also the hybrid HyFlex teaching and learning, where students may choose whether to have in-class or online learning.

Although it is believed that in most universities a new hybrid model of education will emerge, with significant benefits, it will most certainly be accompanied by e-learning courses. The latter allows students who have a parallel professional life and/or live far from universities, to also have an opportunity.

The SSVC Course grants this opportunity, contributing to the dissemination of knowledge worldwide, by providing all students anywhere with a means to proceed with their training and qualifications. Meanwhile, the format used also fits perfectly as part of a university course. We believe courses set up in this format are crucial for the readiness that we need to have in facing the next pandemic, which most probably will be inevitable.

UNESCO IESALC (2020) refers that now is the best time to plan our way out of the crisis, undertaking a pedagogical review and renewal that favors both quality and equality. Some of the priorities are "ensuring the right to higher education of all persons within a framework of equal opportunities and nondiscrimination", "leaving no student behind", "rethinking/redesigning the teaching and learning processes, taking advantage of the lessons that the intensive use of technology may have entailed".

As pointed out by Mishra et al (2020), previously, e-learning, distance education, and correspondence courses were popularly considered as part of nonformal education, but as of now, it seems that they may gradually replace the formal education system.

\section{4 - Impact of communication skills and strategies on research}

Researchers need to be able to develop the necessary communication skills to effectively convey the significance of their research, particularly outside the immediate environment of their subject area. This may be relevant in various situations like grant applications, oral presentations in conferences, written publications, job applications, and communicating with the media.

According to the University of Ghent's Doctoral training course on communication skills, a researcher needs to make the case for why his/her research matters, defining his/her contribution to the field. Also, it is important to find the story in one's research and know how to announce it to eventually make the headlines. Additionally, the researcher needs to know how to communicate the possible applications of his/her research. Finally, transmitting further research that could help to stimulate and promote, and the impacts it may have (Ugent, 2021)

\section{1 - Communication skills in clinical trials}

In clinical trials, in particular, it is essential to monitor communication effectiveness to ensure that effective solutions are developed to prevent negative consequences, like lack of compliance, harm to subjects, waste of time, ineffectiveness, difficult relationships, and invalidation of data. Communication skills and strategies are essential to overcome this, therefore learning soft skills is imperative.

Furthermore, as referred by Pick et al (2014), informed consent is fundamental to the protection of the rights, safety, and wellbeing of patients in clinical 
research. For consent to be valid, effective communication has to ensure that patients' tutors are given all the information they need to be able to decide whether to participate.

Parreco et al (2012) emphasize that improving the communication skills, that clinicians use when explaining trials, could resolve patients' tutors' concerns, increasing the likelihood of their participation, greater compliance, and a lower drop-out rate.

\section{5 - Improving evidence-based practice}

Evidence-based practice is considered to be essential for quality patient care. It may be described as care that is guided by high-quality evidence from research but contextualized and appropriated to suit each situation. However, there seems to be limited clinicians' adherence to indicators of appropriate care. How evidence-based practices are communicated to healthcare professionals can influence the ways they engage with and use this information. Accordingly, information should be communicated via credible sources such as peers, to ensure confidence in its use. The perceived opinions of peers and opinion leaders are crucial in influencing the decision of individual practitioners to act on new information (Dadich and Hosseinzadeh, 2016). Communication skills and strategies are therefore of utmost relevance in improving evidence-based practice.

There are also various challenges in the communication of research evidence to patients' tutors in practice. As van Bekkum and Hilton (2013) point out, normal communication models are not sufficient to deal with patients' tutors' anxieties. Patients' tutors are increasingly critically minded and becoming more proactive in assessing evidence themselves, which in turn is having an impact on health care professional's confidence to communicate the best evidence. Therefore, managing and maintaining long-term positive relationships with patients' tutors is crucial to facilitate effective communication of research evidence, making the acquisition of communication skills mandatory.

\section{6 - Limitations of the course}

Some limitations need to be accounted for. It is advisable to be connected to a university, foundation, or professional society, for logistic, administrative, financial, and personnel support. The initial cost and running cost of synchronous learning can be high. Additionally, the right time zone needs to be chosen for the synchronous activities, to be feasible for students from various parts of the world. The language skills of teachers and students have to ensure communication is possible. Staff team effort is of extreme importance to motivate students and give them a sense of belonging. A good online platform, an efficient internet connection, and accessibility to course materials are essential. Also, student readiness has a great impact on the course success, therefore having the necessary technology (suitable computer and internet access) is crucial. Moreover, evaluation has to be fair but at the same time honest and reliable, therefore, well-specified guidelines (scorecards) have to be issued to avoid role-play assessment being subjective.

Students may feel more isolated, require more time studying and completing assignments than in a presential course and it is easier to procrastinate, so they need to be active learners and have good time management skills. Students need to find their path to learning and need to be responsible for their learning. However, some people need their progress to be closely monitored to perform. Also, online learning has many opportunities for distractions, both from personal life and from the internet itself.

Moreover, there can be practical limitations of the role-play activity if, for example, a student playing the role of a patient is not consistent with the diagnosis or, on the other hand, reveals some clear diagnostic hints.

Giving constructive feedback on time is essential, as well as keeping efficient track of all students' questions, to make them feel support and reassurance, and decrease the drop-out rate. Nevertheless, nothing can completely replace human contact. Furthermore, in a communication course, like this one, it is of the utmost importance to make sure that there are no barriers to listening, accurate perception, and effective verbal communication.

Finally, when creating an online course that proves to be effective, it is mandatory, amongst other things, to have time, experience, commitment, good communication skills, and a true passion for learning.

\section{CONCLUSIONS}

Based on the characteristics of this course, we estimate it to be a novel element, capable of developing soft skills in veterinarians, even during pandemic times. We believe that this is the first course on veterinary communication skills and strategies which is completely carried out by e-learning. Furthermore, the structure of the course and the methodology used may contribute to promoting student adherence and 
satisfaction, patient care, and professional fulfillment. It could also contribute to clinical research and evidencebased practice.

At the end of the course, we encourage students to apply for the "Bayer Excellence in Communication Award". For the application, they are invited to submita filmed interview between themselves and a veterinary client in a clinical setting.

\section{Acknowledgments}

We would like to thank Professor Felipe Fregni and Professor Maria Helena Rigatto for all their helpful comments and orientation on drafts of this course project.

\section{Conflict of interest}

None.

\section{REFERENCES}

Adams, C. and Kurtz, S. (2017) Skills for communicating in veterinary medicine. NJ, U.S.A.: Dewpoint Publishing.

Artemiou, E, Adams, C., Hecker, K., Vallevand, A., Violato, C., Coe, J. (2014) Standardised clientes as assessor in a veterinary communication OSCE: a reliability and validity study. Veterinary Record, 175(20):509.

Bard, A., Main, D., Haase, A., Whay, H., Roe, E., Reyher, K. (2017) The future of veterinary communication: Partnership or persuasion? A qualitative investigation of veterinary communication in the pursuit of cliente behaviour change. PLOS ONE, 12(3): 0171380.

Bintley, H., Easton, G., George, R., Raval, D., Wells, H., Ehamparanathan, N., Le Voir, H., Wright, S., Evans, D., Rowlands, A., Shafi, A. (2021) Twelve Tips for teaching clinical and communication skills online. Medical Teacher Journal, 4. Available from: https://www.mededpublish.org/manuscripts/3743

Bolliger, D. and Martin, F. (2018) Instructor and student perceptions of online student engagement strategies. Distance Education, 39(4)568583.

Cake, M., Bell, M., Williams, J., Brown, F., Dozier, M., Rhind, S., Baillie, S. (2016) Which professional (non-technical) competencies are most importante to te success of graduate veterinarians? A best evidencemedical education (BEME) systematic review: BEME Guide no. 38. Medical Teacher, 38(6):550-563.

Dadich, A, Hosseinzadeh, H (2016) Communication channels to promote evidence-based practice: a survey of primary care clinicians to determine perceived effects. Health Research Policy and Systems, 14, 62.

Fregni, F. (2019) Critical thinking in teaching and learning. Massachusetts, USA: Lumini LLC. 127 pages.

Fregni, F. and Sanchez, A. (2020) Evidence-based analysis of technology in teaching and learning. Boston, USA: Felipe Fregni and Alma Sanchez Jimenez.

IHC Veterinary Communication Modules (2021). Available from: https://healthcarecomm.org/veterinary-communication/ihcveterinary-communication-modules/

Hattie, J., Donoghue, G. (2016) Learning strategies: a synthesis and conceptual model. NPJ Science of Learning, (1):16013.

Jones, F., Passos-Neto, C., Braghiroli, O. (2015) Simulation in Medical Education: brief history and methodology. PPCR, 1(2):46-54.
Kanara, E. and Werner, H. (2012) Improving your equine practice by enhancing the veterinary-client-patient relationship. In: Welfare and wellness: improving the lives of horses and veterinarians. American Association of Equine Practitioners (AAEP) Proceedings, 58:317-319.

Kurtz, S. (2006) Teaching and Learning Communication in Veterinary Medicine. Journal of Veterinary Medical Education 33(1):11-9

Li, C and Lalani, F (2020) The COVID-19 pandemic has changed education forever. This is how. World Economic Forum, 29th April.

McDermott, M. (2018) Veterinary communication skills and training in the United Kingdom and the United States of America. PhD thesis, University of Nottingham.

Mishra, L, Gupta, T, Shree, A (2020) Online teaching-learning in higher education during lockdown period of COVID-19 pandemic. International Journal of Educational Research Open, 1, 100012.

Moore, D., Sischo, W., Kurtz, S., Siler, J., Pereira, R., Warnick, L. (2016) Improving dairy organizational communication from the veterinarian's perspective: results of a continuing veterinary medical education pilot program. Journal of Veterinary Mdical Education, 43(1):22-40.

Moreno-Guerrero, A, Rodríguez, C, Gómez Garcia, G, Navas-Parejo, M (2020) Educational innovation in higher education: use of role playing and educational video in future teacher's training. Sustainability, 12, 2558.

Nestel, D and Tierney, T (2007) Role-play for medical students learning about communication: Guidelines for maximising benefits. BMC Medical Education, 7 (3).

Parreco, LK, DeJoice, RW, Massett, HA, Padberg, RM, Thakkar, SS (2012) Power of an Effective Clinical Conversation: Improving Accrual Onto Clinical Trials. Journal of Oncology Practice, 8, 5, 282-286.

Pick, A, Gilbert, K, McCaul, J (2014) The role of effective communication in achieving informed consent for clinical trials. Nursing Standard, 29, 10, 45-48.

Pun, J. (2020) An integrated review of the role of communication in veterinary clinical practice. PUN BMC Veterinary Research, 16:394.

Royal College of Veterinary Surgeons (RCVS) (2001) Veterinary Education and training - a framework for 2010 anf beyond. A consultation paper prepared by the RCVS Education Strategy Steering Group, July 2001. London: RCVS. Available from: https://www.rcvs.org.uk/documentlibrary/essg-consultation-document-2001/

Royal College of Veterinary Surgeons (RCVS) (2020) Day One Competences. A paper prepared by the RCVS Education Department. London: RCVS. Available from: https://www.rcvs.org.uk/document-library/day-onecompetences/

Serin, H. (2018) The Use of Extrinsic and Intrinsic Motivations to Enhance Student Achievement in Educational Settings. International Journal of Social Sciences and Educational Studies 5(1)191-194.

Shellenberg, S., Negishi, M., Eggen, P. (2011) The Effects of Metacognition and Concrete Encoding Strategies on Depth of Understanding in Educational Psychology. Teaching Educational Psychology 7(2):17-24.

Taylor, A., Goehler, L., Galper, D., Innes, K., Bourguignon, C. (2010) TopDown and Bottom-Up Mechanisms in Mind-Body Medicine: Development of an Integrative Framework for Psychophysiological Research. Explore (NY) 6(1):29.

https://www.ugent.be/doctoralschools/en/doctoraltraining/courses/trans ferableskills/all/communication-skills.htm

UNESCO IESALC (2020) COVID-19 and higher education: today and tomorrow. Impact analysis, policy responses and recommendations, 9th April. 45 pages. Available from: http://www.iesalc.unesco.org/en/wpcontent/uploads/2020/04/COVID-19-EN-090420-2.pdf

van Bekkum, JE and Hilton, S (2013) The challenges of communicating research evidence in practice: perspectives from UK health visitors and practice nurses. BMC Nursing, 12, 17.

https://www.weforum.org/agenda/2020/04/coronavirus-educationglobal-covid19-online-digital-learning/ 